\title{
Estratégias discursivas da Mídia Ninja no caso do habeas corpus (não) concedido ao ex-presidente Lula
}

\author{
[Discursive strategies of Mídia \\ Ninja in the case of the \\ habeas corpus (not) granted to \\ former president Lula]
}

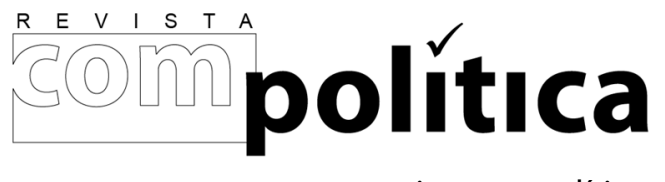

revista compolítica 2019, vol. 9(1)

compolitica.org/revista

ISSN: 2236-4781

DOI: 10.21878/compolitica.2019.9.1.244 (O) Open Access Journal

\author{
Raul Ramalho \\ Universidade Federal do Rio Grande do Norte \\ [Rio Grande do Norte Federal University]
}

\author{
Kênia Maia \\ Universidade Federal do Rio Grande do Norte \\ [Rio Grande do Norte Federal University]
}

\begin{abstract}
Resumo
Este artigo analisa a produção discursiva do coletivo Mídia Ninja, na sua página no Facebook, no que diz respeito ao habeas corpus concedido (e depois negado) ao ex-presidente do Brasil, Luiz Inácio Lula da Silva, no dia 8 de julho de 2018. O trabalho utiliza como metodologia a Análise de Discurso baseada no modelo tridimensional de Fairclough (2001). A pesquisa problematiza o caráter midiativista da Mídia Ninja, ao concluir que o grupo atuou a favor de libertação de Lula, a partir de uma narrativa centralizada e multimidiática (textos escritos, fotos, charges, vídeos e emissões ao vivo) aliada a uma estratégia discursiva contra-hegemônica, elegendo adversários (a exemplo do juiz Sérgio Moro) e heróis (como Lula e o então pré-candidato à presidência, Guilherme Boulos), e apontando a situação como parte de um golpe articulado pela mídia tradicional e por setores das classes política e judiciária.
\end{abstract}

Palavras-chave: Mídia Ninja, Lula, análise do discurso.

\begin{abstract}
This paper analyzes the discursive production by the collective Mídia Ninja, in its Facebook page, regarding to the habeas corpus granted (and later denied) on July 8, 2018 to former president of Brazil, Luiz Inácio Lula da Silva. The work uses as methodology the Discourse Analysis based on the threedimensional model by Fairclough (2001). The research problematizes the media activism feature of Mídia Ninja, concluding that the group acted in favor of Lula's freedom, based on a centralized and multimediatic narrative (written texts, photos, cartoons, videos and live broadcasts) combined with a counter-hegemonic discursive strategy, electing opponents (such as Judge Sérgio Moro) and heroes (such as Lula and the then pre-presidential candidate, Guilherme Boulos), and defining the situation as part of a coup architectured by traditional media alongside political and judicial sectors of society.
\end{abstract}

Keywords: Mídia Ninja, Lula, discourse analysis. 


\section{Estratégias discursivas da Mídia Ninja no caso do habeas corpus (não) concedido ao ex-presidente Lula}

Raul RAMALHO

Kênia MAIA

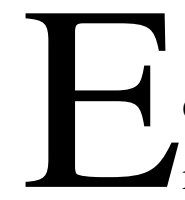

ra pleno domingo (8 de julho de 2018), o Brasil vivia ainda a ressaca da eliminação da seleção brasileira de futebol masculino da Copa do Mundo, realizada na Rússia, evento que dominava o noticiário da mídia corporativa, distribuída nos meios de comunicação tradicionais como rádio, $\mathrm{TV}$, publicações impressas e também na internet. Porém, um fato apareceu de surpresa, sacudiu o país, os meios jornalísticos e as redes sociais online. É que por volta de meio-dia da citada data foi divulgada a notícia de um habeas corpus (impetrado por deputados federais do Partido dos Trabalhadores - PT - na noite da sexta-feira anterior, quando da eliminação da seleção brasileira na Copa) concedido pelo desembargador plantonista do Tribunal Federal da $4^{\mathrm{a}}$ Região (TRF-4), Rogério Favreto, ao ex-presidente do Brasil, Luiz Inácio Lula da Silva. Lula está preso na carceragem da Polícia Federal (PF) em Curitiba, condenado dentro da "Operação Lava Jato" por corrupção passiva e lavagem de dinheiro ao aceitar a promessa de receber (conforme explica a sentença condenatória do então juiz federal de $1^{\mathrm{a}}$ instância, Sérgio $\mathrm{Moro}^{1}$ ) um apartamento reformado (o triplex), como propina enquanto era presidente.

A partir da divulgação da notícia do habeas corpus, iniciou-se uma verdadeira guerra entre magistrados (envolvendo três desembargadores e um juiz de $1^{\mathrm{a}}$ instância) para manter preso ou soltar o ex-presidente. A controvérsia jurídica acabou perto das $20 \mathrm{~h}$ do mesmo domingo, quando o presidente do TRF-4, Carlos Eduardo Thompson Flores, pronunciou-se decidindo manter Lula na prisão ${ }^{2}$. No entanto, não foram apenas os meios jornalísticos tradicionais

\footnotetext{
${ }^{1}$ A íntegra da sentença pode ser acessada no seguinte link: http://estaticog1.globo.com/2017/07/12/sentenca_lula.pdf. Acesso em: 10 jul. 2018.

2 O desenrolar completo dos acontecimentos pode ser observado em: https://brasil.elpais.com/brasil/2018/07/08/politica/1531069948_832628.html; e https://www.nexojornal.com.br/entrevista/2018/07/09/Lula-livre-Lula-preso-uma-an\%C3\%A1liseda-guerra-judicial-de-domingo. Acesso em: 20 jul. 2018.
} 
que fizeram a cobertura desse fato. As mídias-poeira (Ramonet, 2012), que compõem a massa de mídias dispostas na internet e são possibilitadas pelas tecnologias da informação e comunicação (TICs), também acompanharam fortemente o caso.

Muitos desses novos meios atuam contrapondo as visões dos veículos jornalísticos tradicionais, compartilhando com o público seus posicionamentos. Mais do que informar, alguns deles se propõem a atuar em prol de mudanças sociais por meio de uma ação direta em que a rua e o ambiente digital se retroalimentam. Esses grupos fazem midiativismo (Braighi; Câmara, 2018; Foletto, 2017), midialivrismo (Almeida, 2015; Bentes, 2015) ou ciberativismo (Leal, Martins, 2018; Prado, 2015).

Dentro desse contexto, vale destacar o trabalho feito pela Mídia Ninja (MN) na cobertura do citado acontecimento. A partir da publicização da decisão que concedia o habeas corpus a Lula, os sites de redes sociais do coletivo (Facebook, Instagram e Twitter) passaram a compartilhar, em ritmo de atualização contínua - uma característica das possibilidades trazidas pelas TICs (Silva, 2013 apud Leal; Martins, 2018) -, informações, em diversos formatos, sobre o andamento do processo e sobre as manifestações a favor da libertação do ex-presidente, constituindo uma opção para quem tivesse o interesse de acompanhar o caso por uma ótica divergente da dos meios jornalísticos corporativos.

Diante do cenário apresentado, temos a intenção, neste artigo, de fazer uma análise sobre as estratégias discursivas da Mídia Ninja no já explicado processo. Tendo como ponto de partida o fato de que o coletivo é abertamente a favor da libertação do ex-presidente Lula, interessa-nos compreender como se configura essa estratégia discursiva para convencer os internautas sobre a pertinência e validade dos seus posicionamentos e que formatos midiáticos foram utilizados para compor a narrativa sobre o fato. A partir desses objetivos pretendemos discutir duas questões: nesse caso em específico, a $\mathrm{MN}$ praticou midiativismo? Ou apenas fez uma defesa intransigente do ex-presidente, explicitando a parcialidade do coletivo, sem considerar aspectos que justificariam a prisão de Lula?

Neste sentido, a relevância deste estudo está no fato de problematizar a atuação de um coletivo com forte visibilidade no ambiente online e que foi e é tema de muitos estudos acadêmicos: Almeida (2015), Bentes (2015), Prado (2015), Braighi (2016), Foletto (2017), Leal e Martins, (2018), Rodrigues e Baroni (2018). Tomando como base um cenário que 
envolve um símbolo nacional (o ex-presidente Lula), o trabalho contribui para a reflexão sobre: a) as dinâmicas de compartilhamento e distribuição de conteúdos no ambiente digital no contexto da liberação do polo emissor da informação (Ramonet, 2012); b) as relações entre grupos ditos midiativistas e figuras tradicionais do campo político.

Para realizar este trabalho, utilizaremos como metodologia principal a Análise de Discurso, que não se prende à perspectiva textual apenas. É o que explicaremos no próximo tópico.

\section{Notas sobre o método}

Como já foi explicado, esta pesquisa está focada em três fatores específicos: objeto de observação (a Mídia Ninja), contexto (o habeas corpus concedido e depois negado ao expresidente Lula) e lapso temporal (8 de julho de 2018). Diante de tal cenário, este trabalho caracteriza-se como um estudo de caso, que "[...] visa explorar [...] um caso singular, situado na vida real contemporânea, bem delimitado e contextualizado em tempo e lugar para realizar uma busca circunstanciada de informações sobre um caso específico" (Chizotti, 2006, p. 136). Já Yin (2001) associa o estudo de caso a pesquisas que pretendem relacionar o objeto estudado e o contexto que o envolve.

O contexto histórico-social, pois, é justamente um aspecto essencial no que se compreende por discurso, sendo o discurso também constituinte deste contexto:

\footnotetext{
O discurso contribui para a constituição de todas as dimensões da estrutura social que, direta ou indiretamente, o moldam e o restringem: suas próprias normas, convenções, como também relações, identidades e instituições que lhe são subjacentes. O discurso é uma prática, não apenas de representação do mundo, mas de significação do mundo, constituindo o mundo em significado (Fairclough, 2001, p. 91).
}

Para este trabalho, é relevante observar o discurso enquanto prática política e ideológica. Afinal, a MN se insere numa verdadeira guerra contra a hegemonia discursiva de governos, instituições e mídia corporativa: "O discurso enquanto prática política estabelece, mantém e transforma as relações de poder e as entidades coletivas (classes, blocos, comunidades, 
grupos) entre as quais existe relação de poder" (Fairclough, 2001, p. 94). Diante disso, definimos ideologia levando em consideração a seguinte abordagem:

São as significações/construções da realidade (o mundo físico, as relações sociais) que são construídas em várias dimensões das formas/sentidos das práticas discursivas e que contribuem para a produção, a reprodução ou a transformação das relações de dominação (Fairclough, 2001, p. 117).

Já o conceito de hegemonia de Fairclough é trabalhado em diálogo com Gramsci (1971):

\begin{abstract}
Hegemonia é liderança tanto quanto dominação nos domínios econômico, político, cultural e ideológico de uma sociedade. [...] é o poder sobre a sociedade como um todo de uma das classes economicamente definidas como fundamentais em aliança com outas forças sociais, mas nunca atingido senão parcial e temporariamente, como um 'equilíbrio instável'. [...] A luta hegemônica localiza-se em uma frente ampla, que inclui as instituições da sociedade civil (educação, sindicatos, família), com possível desigualdade entre diferentes níveis e domínios (Fairclough, 2001, p. 122)
\end{abstract}

Para o pesquisador, esses dois elementos são essenciais para o entendimento da formação discursiva ou da ordem dos discursos, ou seja, o que contribui para ou dificulta a prevalência de determinados discursos que, por sua vez, são constitutivos de e constituídos por práticas sociais nas sociedades.

Portanto, para fazer a análise discursiva dos posicionamentos da $\mathrm{MN}$ no decorrer dos acontecimentos relativos ao habeas corpus de Lula, utilizamos o modelo tridimensional de Fairclough (2001), observando os seguintes elementos contribuintes para a formação do discurso: o enunciado (o texto, a mensagem em si); a prática discursiva (o contexto imediato da produção, distribuição e consumo dos enunciados, que abarca o formato da publicação, se é vídeo, texto escrito, imagem, imagem sintética feita por computador, e o ambiente onde é publicado); e o contexto histórico-social em que se situam os discursos. 
Figura 1: Concepção tridimensional do discurso, segundo Fairclough

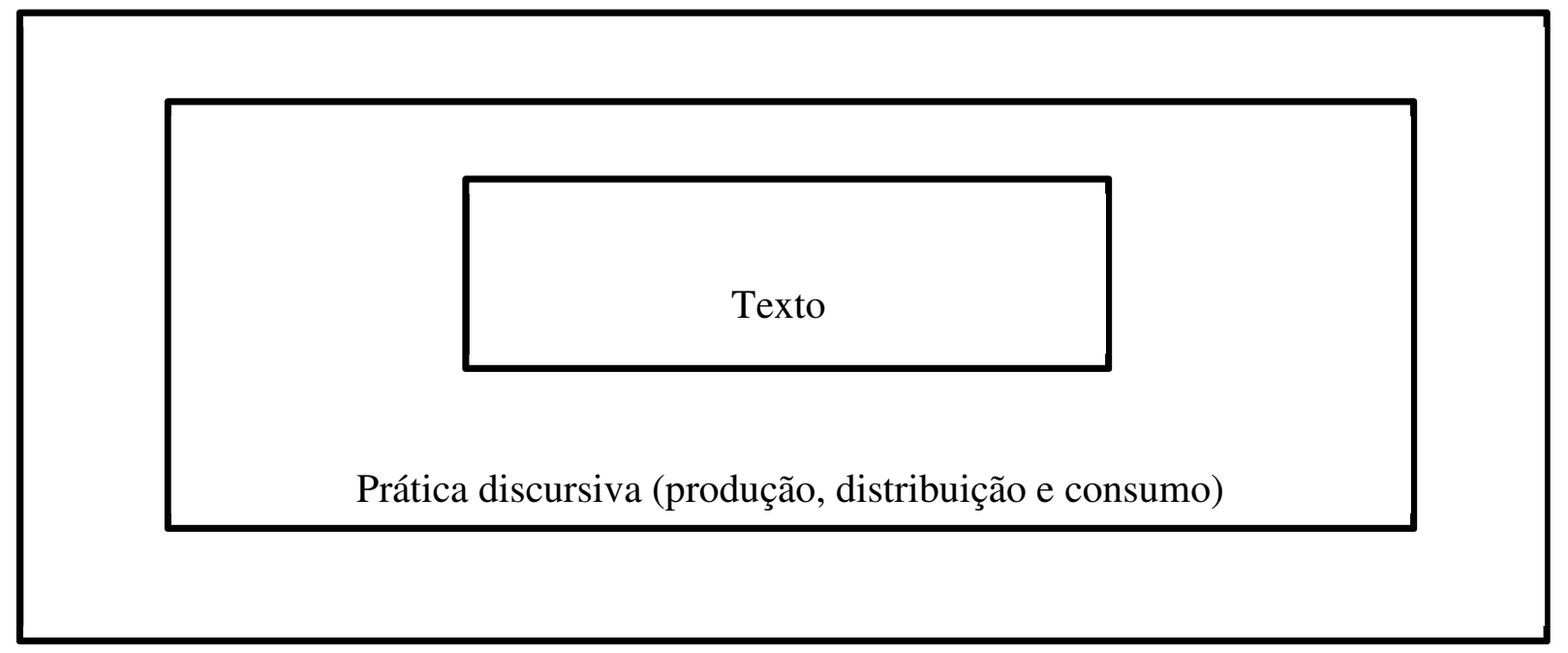

Fonte: Fairclough (2001, p.101)

Vale ressaltar ainda na visão de Fairclough (2001), em concordância com Mainguineau, que este modelo é ideal para analisar discursos em situação de mudança social. Como estamos passando por um processo de mudança social em que as tecnologias e os dispositivos midiáticos assumem papel fundamental nas relações humanas (Castells, 2017; Lévy, 2017), entendemos que esta perspectiva é pertinente para o atual estudo. Além disso, Ramalho e Maia (2018) apontam esse modelo metodológico como bastante pertinente para estudar os discursos de coletivos midiativistas, a exemplo da MN.

Agregando uma perspectiva mais atual à Análise de Discurso, Mainguineau (2015) aborda os formatos enunciativos pulverizados na internet e nos sites de redes sociais. Para ele, esses novos formatos e os impactos do contexto digital nos discursos (a exemplo da flexibilização da figura do autor, os novos formatos enunciativos das postagens em sites de redes sociais - reações, compartilhamentos, hashtags ${ }^{3}$ - e a diminuição das limitações de produção, circulação e consumo de enunciados) são elementos relevantes que devem ser

\footnotetext{
${ }^{3}$ Malini e Antoun (2013, p. 196) explicam que as hashtags são um tipo de ferramenta dos sites de redes sociais que funcionam "agregando todos os relatos sobre determinados assuntos, gerando memórias dos fatos cotidianos com a possibilidade das enquetes dos assuntos do momento (popularmente chamados de "ranqueamento") e a transformação dos relatos fragmentados em notícias gerais e comuns".
} 
considerados pelo analista que pretende se embrenhar na tarefa de estudar os discursos na internet.

Com relação ao trabalho analítico em si, faremos a observação na página da MN no Facebook $^{4}$, pois essa ambiência, no nosso entender, tem uma forte perspectiva de enfrentamento e atualização contínua. Além disso, não é necessário recorrer a outras plataformas utilizadas pelo coletivo, a exemplo do Twitter ou do Instagram, pois o que pode mudar é o formato dos enunciados (uma adequação ao meio), mas o discurso permanece essencialmente o mesmo.

Para coletar as postagens analisadas, utilizamos a ferramenta NetVizz ${ }^{5}$ que colhe automaticamente os links das postagens, bem como a mensuração do engajamento das mesmas nas páginas do Facebook. A coleta das postagens foi feita no dia 09 de julho de 2019, dia seguinte aos acontecimentos (divulgação da possível liberação de Lula e decisão final determinando a continuidade da sua prisão). Ao todo, foram coletadas 73 postagens sobre o tema, todas do dia 08 de julho.

Objetivamente, foram analisadas seis postagens que tinham formatos variados: texto escrito, montagem gráfica, emissão ao vivo, charge, compartilhamento de link de outros sites e compartilhamento de link do site oficial da MN. Essas seis foram selecionadas para que pudéssemos abranger uma maior variedade de formatos utilizados pelo coletivo para realizar suas coberturas. No entanto, ressaltamos que, na contextualização da análise, nos referimos a outras publicações do grupo sobre esse assunto no mesmo dia com a intenção de dar mais coerência ao estudo.

Assim, podemos dizer que ao fazer essas relações com outras postagens de maneira mais superficial, referimo-nos à prática discursiva e à prática social, embora em alguns momentos façamos relação com o texto em si para ilustrar melhor a análise. Com bem explica Fairclough (2001) e Ramalho e Maia (2018) é na criatividade do analista e na

\footnotetext{
${ }^{4}$ Em 05 de fevereiro de 2019, a Mídia Ninja possuía cerca de dois milhões de seguidores no Facebook.

${ }^{5}$ De acordo com Recuero (2017: p. 42) o Netvizz "funciona via Facebook e para o Facebook. Coleta dados de grupos e de páginas de busca e permite que sejam exportados. Permite busca de conexões entre as páginas e outras ações (...). Seu uso é relativamente simples, mas a coleta de dados pode ser bastante demorada".
} 
capacidade do mesmo em fazer as relações entre o texto, o micro e o macro contexto que reside a possibilidade de a análise discursiva se aproximar com mais efetividade dos objetivos propostos.

Antes de adentrarmos no trabalho interpretativo, é necessário delinear conceitualmente a Mídia Ninja, considerando o cenário tecnológico-social que contribui para a sua emergência e as visões teóricas que tentam dar conta desse fenômeno midiático na atualidade. Isso nos dará propriedade para realizar a análise pretendida.

\section{Contextualizando a Mídia Ninja}

N.IN.J.A.: Narrativas Independentes Jornalismo e Ação. Quatro palavras que dizem muito. Direcionamentos, posicionamentos, o que se propõe fazer. Oficialmente, a Mídia Ninja surgiu em 2013, mas a origem do grupo remete a 2011 com as experiências da PósTV, a partir da estrutura disponibilizada pelo coletivo cultural Fora do Eixo (FdE), contextualizado por Foletto da seguinte forma:

[...] inicialmente um circuito cultural estabelecido por diversos coletivos nas cinco regiões brasileiras, que, depois, seria (e continua sendo até o final de 2016) a principal sustentação do trabalho da Mídia Ninja, com a organização das casas coletivas em diversas cidades brasileiras, que serviam de moradia a seus principais integrantes, em especial a Casa Fora do Eixo São Paulo; e a ação coordenada de uma frente de cobertura de acontecimentos diversos, inicialmente shows e festivais musicais, como Mídia Fora do Eixo, depois manifestações e outras ações de protestos nas ruas das grandes cidades, como PósTV e, finalmente, Mídia Ninja (Foletto, 2017, p. 82).

Com o sucesso da PósTV, a massificação do uso das redes sociais digitais e a popularização das plataformas que ambientam essas redes, principalmente Twitter e Facebook, o braço midiático do FdE ganha relevância, recebendo a denominação de Mídia Ninja, no ano de 2013. E é nesse ano que o grupo ganha evidência ao realizar coberturas das manifestações de junho no Brasil, principalmente por meio de emissões ao vivo via Twitcasting, quando protestos começaram na cidade de São Paulo contra o aumento das passagens do transporte público e tomaram praticamente todo o país por motivos diversos: reivindicações por 
melhorias na saúde, educação e segurança, por exemplo, e questões locais (Foletto, 2017; Prado, 2015).

Um dos fatores que contribuíram para o sucesso da MN nessas coberturas é que os manifestantes hostilizaram os jornalistas de meios de comunicação empresariais, fazendo com que a imprensa tradicional praticamente não cobrisse os protestos nas ruas, refugiando-se em sacadas de prédios ou em helicópteros. Diante deste cenário, a MN se destacou ao divulgar imagens em tempo real de dentro das manifestações e apoiar as mesmas, obtendo forte alcance devido às possibilidades de propagação de conteúdos nos sites de redes sociais (Bentes, 2015; Braighi, 2016).

Pela descrição apresentada no site oficial, o grupo, hoje com cerca de dois milhões de apoiadores distribuídos em todo o Brasil, quer ser um contraponto ao que é apresentado ao público pela mídia tradicional. Mas, além disso, quer ser um ente ativo na luta por mudanças sociais no Brasil (Mídia Ninja, 201-).

No que diz respeito à forma de atuação no ambiente digital, a MN se distribui em diversas plataformas chamadas por Recuero (2009) de sites de redes sociais (Facebook, Instagram, Twitter, Youtube), além de possuir um site oficial com conteúdos que incluem colunas e notícias sobre diversos assuntos ligados a lutas das minorais e à defesa de direitos sociais, ou mesmo críticas a governos e partidos do campo político de direita. Os formatos narrativos são diversos: emissões ao vivo, fotografias, textos, vídeos, artes gráficas.

Em suma, o coletivo assume hoje um papel relevante no contexto do que Bosco (2017) define como o novo espaço público brasileiro. O estudioso destaca a característica heterogênea dessa nova esfera de discussões calcada nas redes sociais digitais, marcada por conflitos e linchamentos digitais. É nesse ambiente tumultuado que os coletivos midiativistas, a exemplo da MN, buscam visibilidade. Bauman (2018) também destaca o elemento conflitivo das redes sociais digitais e questiona esse suposto elemento democratizador da internet. Para ele, no mundo online, as pessoas tendem a se fechar para visões e posicionamentos diferentes dos seus, formando as chamadas bolhas, o que dificulta o diálogo racional efetivo. 
Ao contrário do pensador polonês, Castells têm uma visão bem otimista sobre o que a internet pode fazer pela luta em prol da democracia e pelos movimentos sociais, os quais podem atuar em redes mais amplas e conectadas, processo facilitado pelas TICs:

[...] o papel da internet ultrapassa a instrumentalidade: ela cria as condições para uma forma de prática comum que permite a um movimento sem liderança sobreviver, deliberar, coordenar e expandir-se. Ela protege o movimento da repressão de seus espaços físicos liberados, mantendo a comunicação entre as pessoas do movimento e com a sociedade em geral na longa marcha da mudança social exigida para superar a dominação institucionalizada (Castells, 2017, p. 198-199).

Concordamos com a visão de Castells no que diz respeito às possibilidades emancipatórias da internet, porém absorvemos a criticidade de Bauman, que aponta a internet como "bênçãos e maldições tornadas inseparáveis" (2018: p. 103). Entendemos que o ambiente online pode ser perigoso, muito por causa da concentração de poder nas mãos de poucas corporações transnacionais, a exemplo de Google e Facebook, e devido também à excessiva vigilância que é exercida por instituições que detêm o poder político (Lévy, 2017; Pariser, 2011). Esse contexto de vigilância e monopólio, de um jeito ou de outro, influencia na produção e no consumo de informação nos sites de redes sociais, embora não seja claro se ou como os coletivos midiativistas se preocupam com esta situação.

\section{Formas de agir e buscar mudanças nos contextos digital e físico}

Apesar dos enfoques diferenciados, as pesquisas apontam o caráter inovador do trabalho dos Ninjas e os colocam como midiativistas (Braighi, 2016), ciberativistas (Prado, 2015) ou midialivristas (Almeida, 2015; Bentes, 2015). Foletto (2017), no entanto, defende que não se deve tentar enquadrar a Mídia Ninja em determinado conceito, pois a forma de atuação do grupo é bastante fluída e é o fato em específico que vai determinar a característica da narrativa, que pode ser mais relacionada ao jornalismo ou ao ativismo. Rodrigues e Baroni (2018) encontraram diversas semelhanças entre o modo de produção de "notícias" da MN e o modo de produção dos jornalistas nas redações tradicionais, tais como critérios de noticiabilidade e filtros que ajudam na tomada de decisões sobre o que 
deve ou não ser publicado. De toda forma, há uma forte concordância em pelo menos dois aspectos: o caráter contestador e ativista do coletivo e as TICs (principalmente a internet) como elementos potencializadores dos conteúdos, discursos e ações compartilhados nas diversas plataformas digitais ocupadas pelo grupo.

Com relação ao debate teórico sobre midiativismo, ciberativismo e midialivrismo, Braighi e Câmara (2018) defendem que são conceitos diferentes. O último conceito estaria mais relacionado à luta por uma democratização da mídia, "que contrasta com o caráter genérico do midiativismo como prática - que pode se relacionar a qualquer causa" (Braighi; Câmara, 2018, p. 29). Já o ciberativismo, para eles, tem uma perspectiva de relações no ambiente digital, sem necessariamente fazer uma ponte com as ruas, perspectiva também apontada por Di Felice (2017). Para este último pesquisador, o termo ciberativismo diz respeito à primeira fase do net-ativismo, na década de $1990^{6}$, quando se começou a experimentar formas de organização online que em sua grande maioria não chegavam ao mundo físico, sendo que o termo ciberativismo é associado também à cultura hacker.

Segundo Di Felice (2017), o net-ativismo, da maneira que se delineia hoje, apresenta as seguintes características (entre outras): origem dos movimentos nas redes digitais, fazendo um movimento de retroalimentação com o ambiente físico, mas permanecendo sempre online para midiatizar os movimentos; não centralização na luta pelo poder (esses movimentos não querem tomar o poder); descentralização das ações em redes distribuídas; ausência de hierarquias formais; desenvolvimento de uma cultura antipersonalística; tendência à desaparição; defesa da liberdade de acesso de todos a todas as informações.

O net-ativismo então não teria o ser humano como elemento central, mas uma complexa organização reticular, não mapeável pelas metodologias sociológicas tradicionais, que materializaria a ação a partir do ato-conectivo, realizado dentro do mundo digital, porém atópico ${ }^{7}$, entre actantes humanos e não-humanos (Di Felice, 2017).

\footnotetext{
6 Para Malini e Antoun (2013), em 1984, a rede mundial de computadores é nomeada como o Protocolo Internet: "(...) é o ano em que surge o ciberativismo como sinônimo de ações coletivas coordenadas e mobilizadas coletivamente através da comunicação distribuída em rede interativa (2013, p. 20).

7 "[...] lugar atípico, fora do lugar, indizível" (Di Felice, 2017, p. 10).
} 
Porém, de acordo com Braighi e Câmara (2018), o diferencial no ato midiativista é justamente o sujeito midiativista ${ }^{8}$ que atua na relação entre a rua, dispositivo midiático mediador e ambiente online:

\begin{abstract}
Midiativismo só se faz com midiativistas, sujeitos portadores de uma vontade solidária, que empreendem ações diretas transgressivas e intencionais, e veem as próprias capacidades de intervenção social, antes localizadas, sendo potencializadas. Isso, por meio de um registro midiático que visa necessariamente amplificar conhecimento, espraiar informação [principalmente através da internet], marcar presença, empreender resistência e estabelecer estruturas de defesa (Braighi; Câmara, 2018, p. 36).
\end{abstract}

Trata-se, no contexto deste trabalho, de reconhecer a essencialidade da técnica, materializada nas TICs, porém não subestimar a importância do humano no trabalho midiativista, termo que utilizaremos, portanto, para designar a Mídia Ninja. Afinal, são humanos com intencionalidades, subjetividades e defeitos que se propõem a atuar no mundo digital e físico com o objetivo de contribuir para a mudança da realidade social (seja ela online ou offline), que lutam em várias frentes (não têm uma causa específica), elegendo suas bandeiras, sem anonimato e utilizando-se de vários formatos e narrativas para fazer valer suas estratégias discursivas.

No entanto, consideramos que a MN também é midialivrista, pois a luta pela democratização da informação em contraposição ao que os meios jornalísticos corporativos tradicionais publicam (Almeida, 2015; Bentes, 2015; Malini e Antoun, 2013) também é uma bandeira do coletivo. Há de se considerar ainda a visão de Leal e Martins (2018) que identificam características conceituais midiativistas, ciberativistas e midialivristas na MN. Concordamos com as autoras no sentido de perceber a pluralidade deste coletivo, que não está preocupado em se encaixar em qualquer definição e, sim, pretende realizar suas ações a partir de quaisquer possibilidades trazidas pelas TICs.

Neste sentido, poderemos dizer então que a MN pode fazer parte, quando pensar ser necessário, de movimentos net-ativistas (segundo a perspectiva de Di Felice, 2017), quando

\footnotetext{
${ }^{8}$ Castells (2017) reforça a necessidade da comunicação entre as pessoas (das mais diversas formas possíveis) para que a ação ativista seja desenvolvida.
} 
os temas levantados por esses movimentos estiverem de acordo com as visões do coletivo citado ou houver condições técnicas, financeiras, temporais (pois o tempo no trabalho de quem faz coberturas informativas é uma variável pertinente) de aderir a esses movimentos em âmbito digital.

Mas a pergunta permanece: e no caso do habeas corpus do ex-presidente Lula quais foram as estratégias discursivas da cobertura feita pela $\mathrm{MN}$ para expor seu ponto de vista? Essa cobertura se enquadraria no ativismo social e no midiativismo? É o que nos propomos a problematizar a seguir.

\section{O discurso da Mídia Ninja no caso habeas corpus do ex-presidente Lula}

A Mídia Ninja fez a primeira postagem no Facebook sobre a concessão do habeas corpus de Lula, às 12h22min, do dia 8 de julho de 2018 (domingo). Foi uma postagem simples, um texto escrito, mas com letras destacadas em negrito, a palavra "urgente" em caixa alta e com exclamação, antecedendo o já descrito texto. Para fechar a postagem, a hashtag “\#LulaLivre" deu o tom do que defende o coletivo: a soltura do ex-presidente (ver figura 2).

Figura 2: Primeira postagem da Mídia Ninja sobre o habeas corpus de Lula.

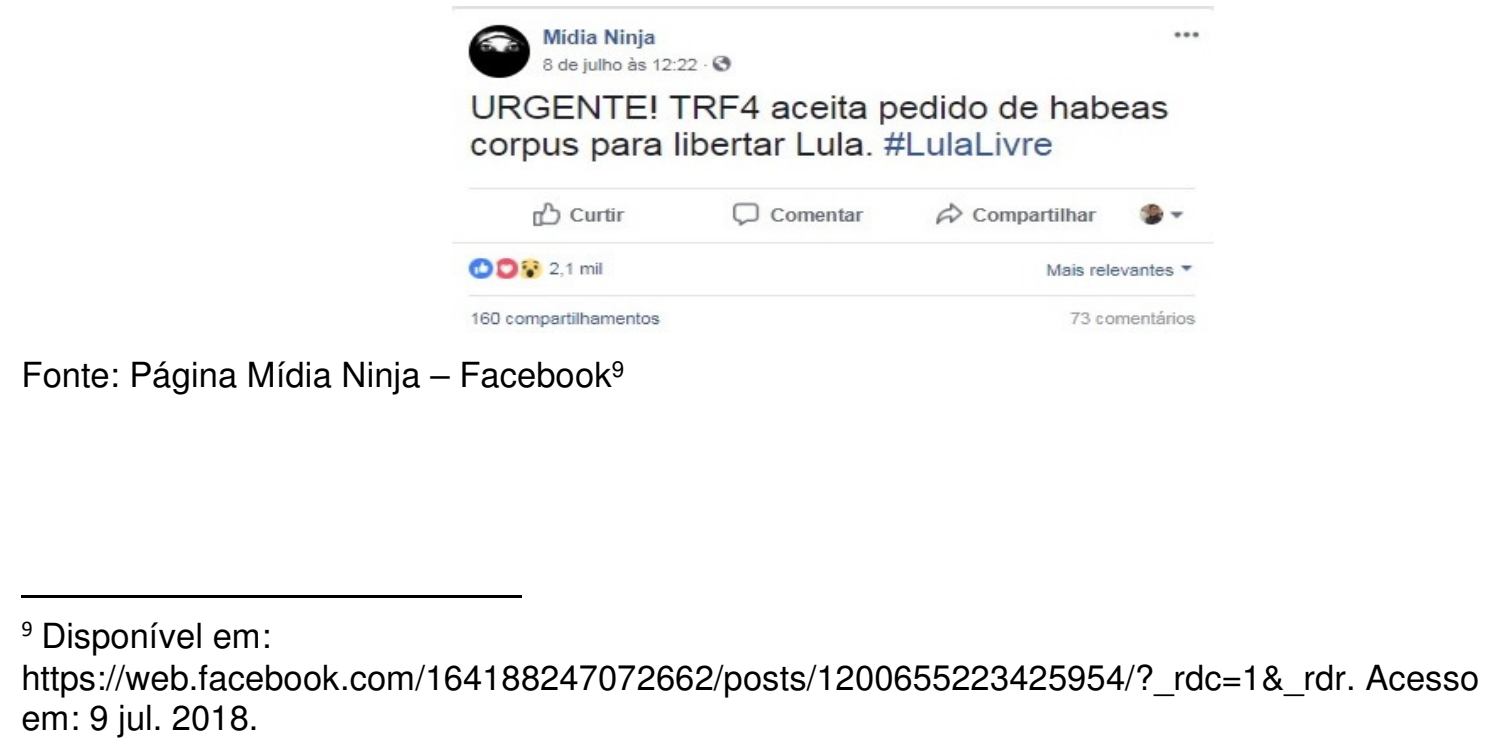


Observando o texto, a prática discursiva e a prática social, como orienta Fairclough (2001), percebemos uma adequação da linguagem ao meio (Facebook, ambiência digital), por meio da hashtag, numa tentativa de dialogar com os milhões de internautas e imergir na torrente discursiva (formada por diversos outros grupos, partidos, indivíduos etc.) favorável ao expresidente Lula. Uma hashtag bastante compartilhada demonstra a força de uma ideia. Era preciso então ganhar a rede digital, dar visibilidade à pressão pela libertação de Lula. Como nos explica Mainguineau (2015), deve-se considerar as particularidades discursivas das redes digitais, as idiossincrasias linguísticas e simbólicas populares na internet, pois elas têm uma ligação direta com o contexto social e tecnológico, para melhor entender os discursos nesses ambientes.

Sobre este tema, esta foi a única postagem em forma de texto escrito puro e simples neste dia. A partir daí ocorreu uma verdadeira enxurrada imagética que constituiu a prática discursiva do grupo neste caso em específico. As postagens (fotos, artes gráficas e produtos audiovisuais, principalmente emissões ao vivo) demonstram a sanha iconofágica da contemporaneidade, como nos descreve Baitello Júnior (2014).

Diante de tal cenário, os Ninjas se utilizaram fortemente das possibilidades trazidas pelas TICs para produzir e compartilhar uma miríade de formatos de imagens. Vale ressaltar que todas elas são acompanhadas por status (o texto escrito que registra a postagem). Identificamos, no que diz respeito aos produtos imagéticos não-audiovisuais, charges, fotos, montagens de fotos e textos para deixar determinada imagem mais chamativa, textos com características de imagens (textos organizados de maneira a realçarem as letras e o plano de fundo para chamar atenção não pelo que dizem, mas pelo design da imagem), prints (capturas de telas de computadores, smartphones ou tablets) com tweets sobre o caso (é texto, mas a partir do momento que é "printado" vira imagem).

Uma dessas imagens é emblemática no que diz respeito à relação histórica (a prática social, na linguagem de Fairclough) que é necessária para melhor entender os fatos do presente e às intencionalidades dos enunciados que formam os discursos. Foucault coloca esse aspecto em sua arqueologia do saber (2008). Falamos sobre a imagem que sobrepõe o rosto de Lula à decisão que lhe concede o habeas corpus (ver figura 3). A imagem do rosto é da época da primeira prisão de Lula, ainda na ditadura militar, por causa da liderança da greve 
de metalúrgicos do ABC paulista, em 1980 (Bezerra, 2011). Uma imagem que ficou marcada no imaginário dos movimentos de esquerda e que foi bastante utilizada por Lula e pelo PT em vários outros momentos, principalmente em campanhas políticas, ajudando a compor a imagem pública e o capital político do ex-presidente (Bezerra, 2011).

Ao utilizar essa imagem do rosto de Lula, com o texto do status defendendo que "precisamos retomar a democracia", a MN relaciona texto e contexto para associar a atual situação àquela de estado de exceção vivida pelo Brasil durante o governo militar. Há também várias outras montagens com imagens de Lula mais recentes, sempre em meio à multidão, abraçando pessoas e exaltando o caráter messiânico e mitológico do expresidente. Infere-se que a ideia é que este tipo de publicação incentive a militância, pelos afetos e sentimentos trazidos pela trajetória de luta de Lula, a encampar o pedido de libertação do mesmo. Percebe-se, portanto, na postagem citada, intertextualidade manifesta (há a sobreposição de dois textos: alvará de soltura e imagem do rosto de Lula) e interdiscursividade, pois esta postagem refaz ligações com outros eventos e momentos histórico-políticos que têm forte significado discursivo na prática social atual (Fairclough, 2001). 
Figura 3: Montagem de Lula sobre cópia da concessão do habeas corpus.

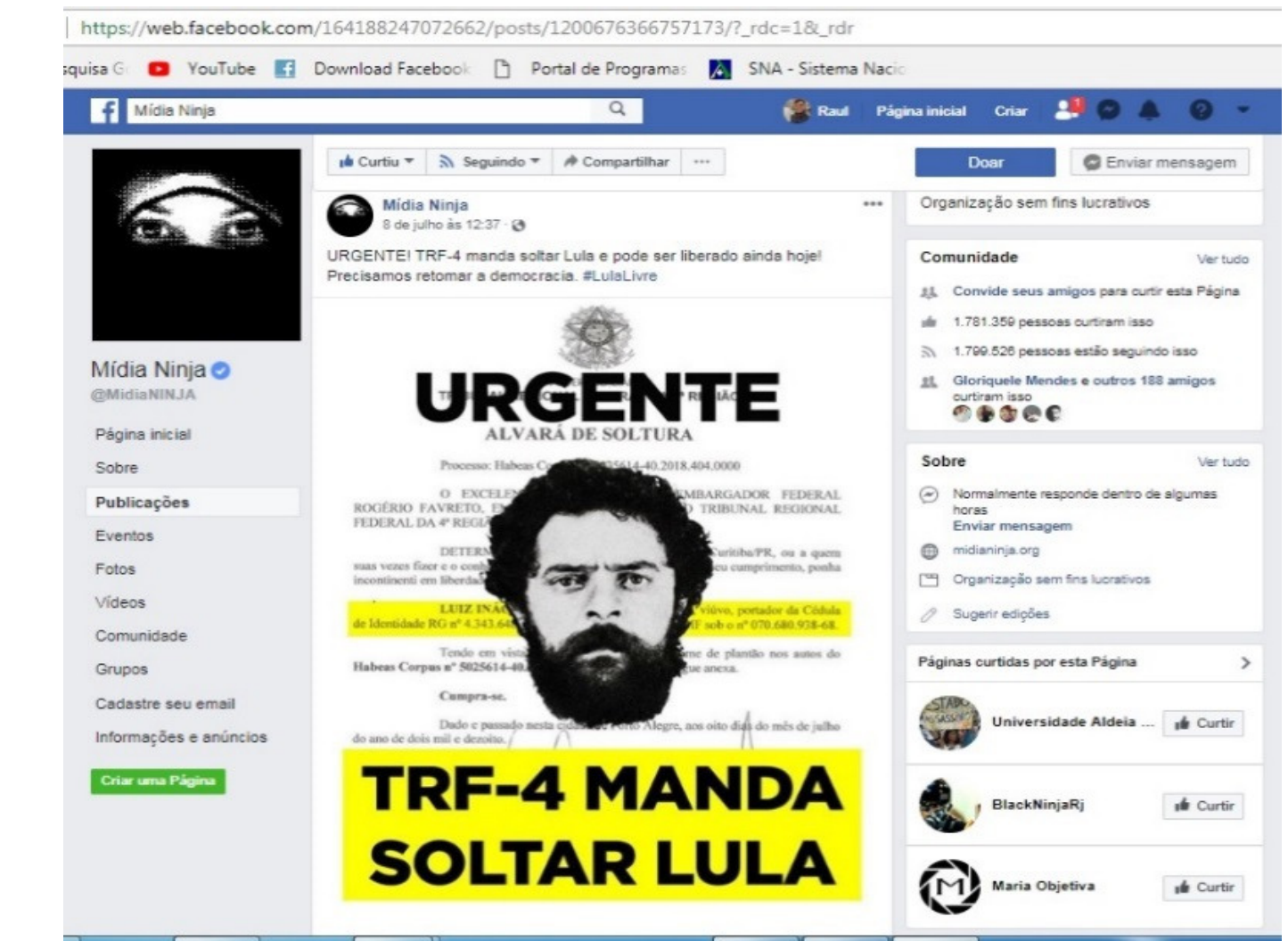

Fonte: Página Mídia Ninja - Facebook ${ }^{10}$

Com relação aos produtos audiovisuais, identificamos que postagens de emissões ao vivo foram preponderantes na prática discursiva dos Ninjas. As emissões não tinham compromisso estético, nem um tempo padrão. Houve transmissões que duraram minutos (dois minutos, cinco minutos, 40 minutos etc.) e uma maior que durou mais de duas horas no ar. A ideia do coletivo é marcar presença (Braighi; Câmara 2018), não importa se a imagem é tremida e se não há informações para passar. A atualização informativa era feita durante a transmissão. Na maioria dos vídeos que mostravam as manifestações não havia a identificação do "repórter" que narrava e caminhava com o celular na mão, no modo câmera subjetiva, "quando o espectador [...] tem o ponto de vista da câmera" (Rodrigues, 2007: p. 33), mostrando a situação e entrevistando pessoas aleatoriamente. Outras vezes, nem narração havia, tratava-se de apenas mostrar o local da manifestação, a emoção das

${ }^{10}$ Disponível em: https://web.facebook.com/164188247072662/posts/1200676366757173/?_rdc=1\&_rdr. Acesso em: 9 jul. 2018. 
pessoas e as demonstrações de afeto ao ex-presidente. Em certos momentos, a transmissão dava problema, faltava bateria, saia do ar, mas voltava, demonstrando a dependência dos dispositivos midiáticos para que tudo funcionasse. Houve emissões ao vivo de manifestações a favor da libertação de Lula nas imediações da sede da Polícia Federal, onde ele está preso, em Curitiba (Paraná), na frente do Sindicato dos Metalúrgicos em São Bernardo dos Campos (São Paulo), na Cinelândia (Rio de Janeiro) e na frente do Supremo Tribunal Federal (Brasília). Neste sentido, percebemos a prática discursiva permeada a todo momento pela diluição das barreiras entre ambiente físico e o digital, pois só a retroalimentação entre os mesmos possibilita que o grupo atinja o objetivo de marcar presença e espalhar a informação (Braighi; Câmara, 2018)

Há de se destacar uma transmissão ao vivo feita pela $\mathrm{MN}$ que tinha um formato peculiar e que demonstra o amadurecimento do grupo com relação ao domínio das técnicas de transmissão, mas levanta um ponto de interrogação no que diz respeito à configuração descentralizada e dialógica assumida pela internet e pelas relações nas redes digitais. Do que parece ser uma casa, localizada em São Paulo (ver figura 4), um apresentador atualizava as informações sobre a situação de Lula e chamava as entradas ao vivo dos vários locais já citados, nos moldes de um telejornal tradicional, obviamente que com características discursivas e estética audiovisual totalmente diferenciadas.

A interação com o público era feita por meio da leitura de comentários na postagem e do pedido para que os internautas compartilhassem as transmissões para que essas fossem assistidas por mais pessoas. Essa transmissão em particular durou mais de duas horas e demonstra uma maior organização informativa do coletivo, o que parece mostrar a tentativa do grupo de ter um maior controle da divulgação dos acontecimentos cobertos, afinal há a possibilidade de começar e encerrar o contato com o local da transmissão quando se bem entender, a partir de uma decisão de uma pessoa ou grupo de pessoas. 
Figura 4 - Plantão Ninja. Print retirado da tela do computador

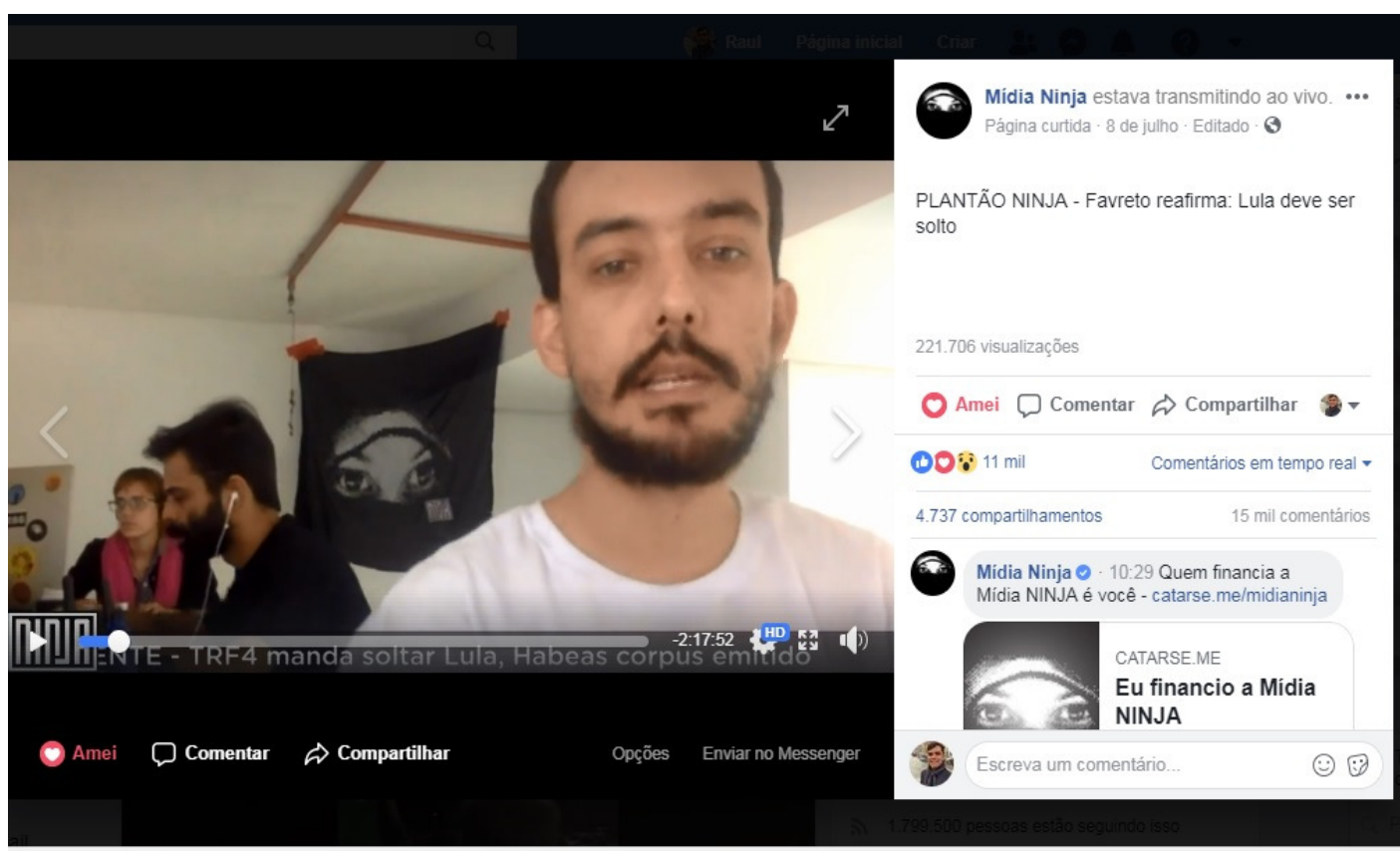

Fonte: Página Mídia Ninja - Facebook ${ }^{11}$

Observamos também um espaço considerável para manifestações de personagens institucionalizados do campo político à esquerda política brasileira: a então senadora do PT-PR e presidenta nacional do partido, Gleisi Hoffmann; o então senador do PT- RJ, Lindbergh Farias; dois dos três deputados que deram entrada no habeas corpus (Wadih Damous e Paulo Pimenta); e, principalmente, o então pré-candidato do PSOL (Partido Socialismo e Liberdade) à presidência da república e líder do Movimento dos Trabalhadores Sem Teto (MTST), Guilherme Boulos, que foi apoiado oficialmente pela Mídia Ninja.

Como mais um fator agregado à prática discursiva da $\mathrm{MN}$, por meio de fotos postadas na página do coletivo e, especialmente, de entradas ao vivo, Boulos atacava o judiciário, o juiz Sérgio Moro (principal símbolo da operação Lava Jato) e a Polícia Federal (PF), exigindo a soltura imediata do ex-presidente Lula, sempre fazendo uma relação com o contexto geral (prática social) da prisão de Lula, do suposto ataque à democracia e do golpe

\footnotetext{
${ }^{11}$ Disponível em: https://web.facebook.com/MidiaNINJA/videos/vb.164188247072662/1201151066709703/?type=2 \&theater. Acesso em: 9 jul. 2018.
} 
que retirou a ex-presidenta, Dilma Rousseff, do poder. Fez-se uma verdadeira narrativa com começo, meio e fim mostrando Boulos ainda em São Paulo, depois no aeroporto de Congonhas a caminho de Curitiba, em seguida dentro do carro, indo do aeroporto de Curitiba ao local da manifestação e, depois, juntando-se aos militantes e líderes do movimento no protesto. Houve, inclusive, um momento em que Boulos atuou como um tipo de repórter, mostrando a movimentação, entrevistando pessoas que estavam no local e, destoando do que um tradicional repórter de TV faria, entoando os gritos de guerra e canções a favor de Lula. Tudo feito com o seu smartphone, caracterizando a mobilidade que as TICs possibilitam no processo comunicativo em redes digitais na atualidade (Silva; Rodrigues, 2014).

A estratégia discursiva de todos os actantes humanos que tiveram espaço nas transmissões era de criminalizar Moro, apontar a parcialidade do judiciário e da PF em todo o processo de investigação e julgamento de Lula, e de exaltar o desembargador Rogério Favreto pela "coragem" (aqui numa perspectiva de colocá-lo como aquele que vai contra o golpe político em curso no Brasil) de soltar Lula. Expressões como "chincana judicial”, "desmoralização do judiciário", "estado de exceção", "golpe", "xerifão", "valentão", "acima da lei” (essas três últimas para se referir a Moro), que nos remetem à necessidade de se observar também o texto no modelo tridimensional de discurso de Fairclough (2001), davam o tom dos enunciados compartilhados nas postagens da MN.

Como nos mostra Mainguineau (2015), existem diversos discursos circulando na sociedade, o discurso jurídico é um deles. Este discurso - formado por enunciados (decisões, sentenças, portarias, habeas corpus, recursos etc.) que se encontram dentro de uma mesma formação discursiva, condicionados por um contexto social e político (Foucault, 2008) - aponta para a culpabilidade do ex-presidente. No entanto, a decisão do desembargador Favreto representa uma dispersão (Foucault, 2008) no contexto judiciário. Ela discorda da maioria das visões no campo jurídico institucional (as diversas instâncias onde acontecem as batalhas recursais).

Porém, essa dispersão tem uma razão de ser. Para entendê-la é preciso observar o contexto político e histórico mais amplo (a prática social). Além das razões processuais apontadas pelo desembargador para conceder o habeas corpus, há todo um processo subjetivo de 
ligação ao PT no histórico do magistrado. Isso não pode ser relegado. Acrescente-se, no entanto, que há outros magistrados ligados a grupos políticos que atuam nos processos da Lava Jato, a exemplo do Ministro do STF, Alexandre de Moraes (que era filiado ao PSDB e foi Ministro da Justiça no governo de Michel Temer), que negou habeas corpus impetrado anteriormente pela defesa de Lula.

Deve-se ainda destacar como os enunciados convergiam na direção de um personagem: o juiz Sérgio Moro, atualmente ministro da Justiça no governo de ultradireita do presidente, Jair Bolsonaro (mais um elemento para compor o complexo contexto social e político que permeia a condenação e manutenção da prisão de Lula). Considerado o grande símbolo da operação Lava Jato e questionado pelos partidários de Lula, Moro interviu numa decisão de um desembargador hierarquicamente superior a ele, enquanto estava de férias. Isso foi fortemente midiatizado pelos meios de comunicação tradicionais e inflamou mais ainda a polêmica em torno da libertação ou não do ex-presidente. Em praticamente todas as falas nas transmissões ao vivo e nas postagens de imagens, Moro era atacado como o elemento central no golpe e que, pela sua visibilidade e conivência dos meios de comunicação corporativos, age como se estivesse acima da lei. Uma narrativa que apresenta Lula como herói injustiçado e Moro como o vilão, representante maior do golpe político, midiático e judicial que toma conta do Brasil, com o intuito de impedir que Lula disputasse as eleições de 2018 (o que de fato aconteceu). Para ilustrar, colocamos aqui uma das charges feitas para criticar Moro e a Rede Globo, outro personagem bastante atacado no discurso dos Ninjas (ver figura 5). 


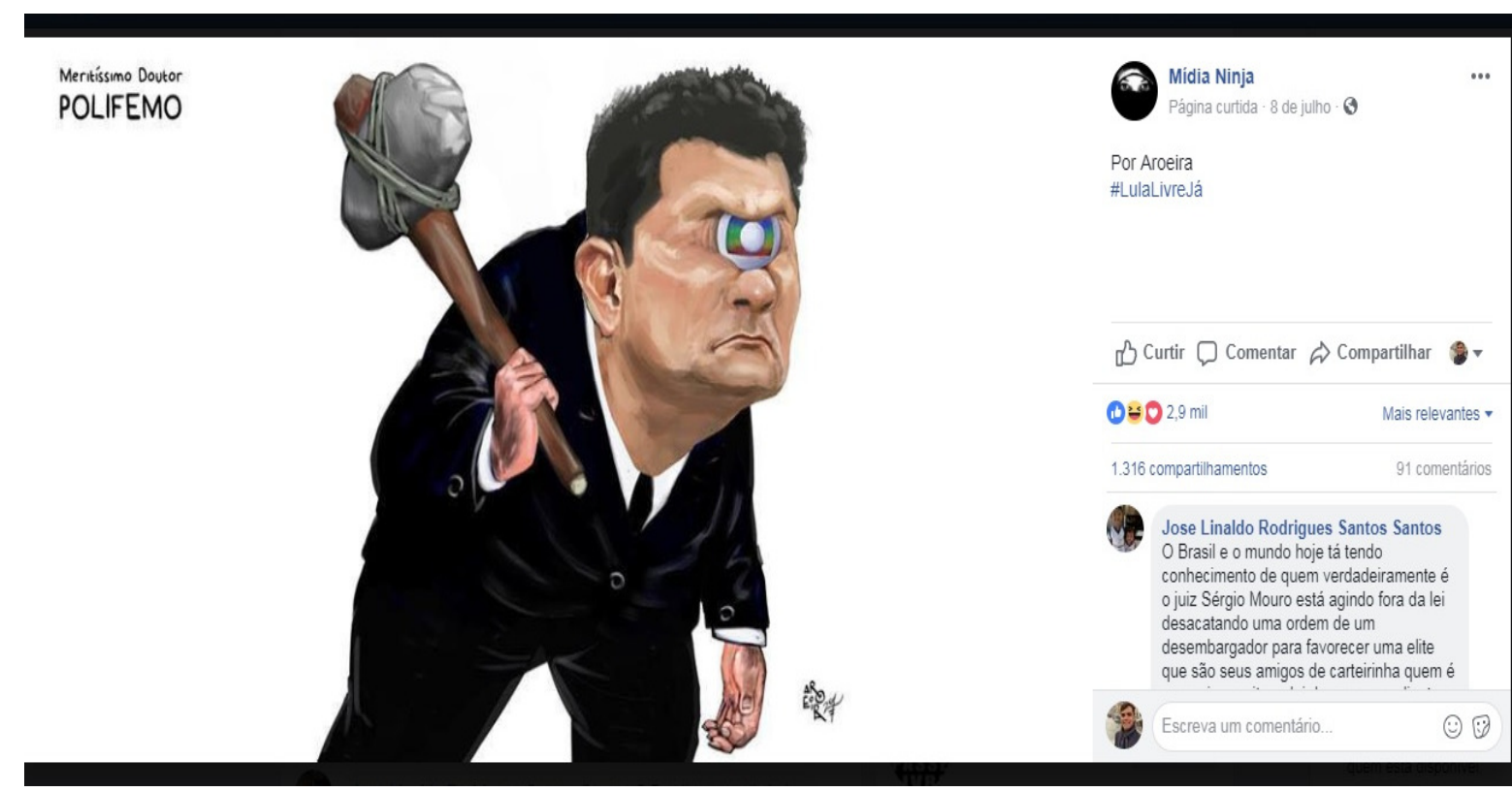

Fonte: Página Mídia Ninja - Facebook ${ }^{12}$

Nesta charge - texto considerado num sentido mais amplo, como aponta Fairclough (2001) -, intertextualidade e interdiscursividade são evidentes. E para compreendê-la é preciso fazer uma relação histórica, literária, política e midiática para compor a prática social que permeia o enunciado. O chargista busca na Odisseia (2014) de Homero, o ciclope Polifemo, reencarnado como Sérgio Moro, cujo único olho é o símbolo da Rede Globo. Ou seja, o juiz só vê o que essa corporação de comunicação (golpista na visão dos defensores de Lula) mostra. É de se destacar o aspecto selvagem do personagem no desenho com o corpo curvado e segurando uma espécie de martelo artesanal, o que demonstra uma crítica à intelectualidade de Moro e à sua capacidade para atuar como juiz.

Por fim, abordamos os links para outras páginas postados durante esse caso de Lula, já que a prática discursiva nos sites de redes sociais é permanentemente composta por estas interligações entre várias ambiências digitais, sendo a intertextualidade manifesta um elemento quase que permanente nos textos postados. Um dos links direcionava para o site

${ }^{12}$ Disponível em: https://web.facebook.com/MidiaNINJA/photos/a.235526863272133.1073741870.1641882470726 62/1200970043394472/?type=3\&theater. Acesso em: 9 jul. 2018. 
da Revista Fórum, com um texto que questiona a legalidade da atuação de Moro, já que ele estava de férias ${ }^{13}$.

O outro link postado direciona para o site oficial da Mídia Ninja, especificamente para o texto de Daniel Zen, que explica por que a decisão de libertar Lula é correta e como o judiciário age parcialmente ao manter o ex-presidente preso. Eis um trecho do texto: "A verdade é uma só: pra lascar o Lula, o PT, a esquerda e o progressismo no Brasil, vale tudo. Até desdizer o direito. \#LulaLivre \#LulaInocente \#LulaPresidente \#TemeréMoro \#MoroéTemereAecio" (Zen, 2018: online. $)^{14}$. O texto em si segue os caminhos de todos os outros enunciados aqui analisados: questiona o judiciário e Moro, coloca a decisão de Favreto como correta e reforça a ideia do golpe.

\section{Considerações finais}

O discurso produzido pela Mídia Ninja no caso da concessão do habeas corpus ao expresidente Lula e a posterior manutenção de sua prisão demonstrou a parcialidade do coletivo no que diz respeito ao contexto político brasileiro que vem desde a eleição de Dilma Rousseff em 2014, passando pelo seu impeachment em 2016. Os Ninjas defendem que Lula é um preso político e corroboram com a narrativa do golpe. A análise feita com base em Fairclough (2001), Foucault (2008) e Mainguineau (2015) revelou que o discurso do coletivo nesse caso em específico seguiu um roteiro: o questionamento do judiciário, a colocação do juiz Sérgio Moro como vilão e de Lula como herói, e a acusação de que judiciário, mídia corporativa, partidos e políticos de direita articularam um golpe que tinha entre seus objetivos o impedimento da candidatura de Lula à presidência da república nas eleições de 2018.

Como estratégia narrativa, a MN se utiliza das possibilidades multimidiáticas oferecidas pelas TICs para compartilhar conteúdos no mundo digital (produtos audiovisuais, fotos, montagens gráficas, hipertextos, emissões ao vivo), fazendo um percurso de

\footnotetext{
${ }^{13}$ Disponível em: https://www.revistaforum.com.br/moro-esta-de-ferias-e-sequer-poderia-estardespachando-contra-lula/. Acesso em: 9 jul. 2018.

${ }^{14}$ Disponível em: https://www.facebook.com/164188247072662/posts/1201156186709191/.

Acesso em: 9 jul. 2018.
} 
retroalimentação narrativa com o mundo físico, já que o estar nas manifestações, a participação nos movimentos, foi algo constante durante o meio tempo entre a concessão do habeas corpus e a revogação do mesmo.

Respondendo à pergunta sobre se a atuação do coletivo configurou midiativismo, consideramos que houve sim, uma ação com objetivo específico através de diversos dispositivos midiáticos, porém, no nosso entendimento, não houve ativismo relacionado a bandeiras sociais ou a direito das minorias. A intenção clara foi defender o ex-presidente Lula, exigir sua libertação e engrossar o movimento em curso que envolve vários grupos e instituições, com mobilizações nas ruas e nas redes digitais, com o intuito de reforçar a narrativa de que ele é um preso político. Não podemos deixar de registrar, porém, que o governo Lula avançou bastante com ações no campo social se comparado ao que foi feito em outros momentos no Brasil (Bezerra, 2011). Consequentemente, para a MN, defender Lula é defender um modelo de gestão que olhe para o social, o que, por outros caminhos, se configuraria como ativismo social.

Outro aspecto é o destaque dado pelo grupo ao fato de que o ex-presidente não tem garantias constitucionais respeitadas no seu processo: prisão com a condenação apenas em segunda instância e, neste caso específico do habeas corpus, a justiça mobilizou-se (com exceção do desembargador Favreto) para manter Lula na cadeia, desrespeitando a hierarquia do judiciário e o andamento normal de recursos. Essas questões, no entender dos Ninjas, apontam para uma ditadura do judiciário que prejudica o Estado democrático de direito.

Observamos também que os discursos da MN, muitas vezes, inserem-se no que Malini (2017) chama de discursos "ladistas" (que se encaixam em um perfil definido no campo político) nos sites de redes sociais, ambientes que no Brasil demonstram uma forte polarização, muitas vezes irracional, no que diz respeito à política (partidária, principalmente).

Quanto à prática discursiva do coletivo, percebemos uma centralização da cobertura, algo a ser discutido em trabalhos posteriores. O que isso significa para a configuração do modelo de atuação da MN e de outros coletivos, já que a descentralização das informações na rede digital é uma característica do midiativismo, como apontam, por exemplo, Bentes (2015) 
e Malini e Antoun (2013)? Como se organizam os filtros que permitem ou não a divulgação de determinada informação, nos moldes do que acontece no jornalismo tradicional? Rodrigues e Baroni (2018) mostraram que a proximidade com os movimentos sociais de esquerda é um forte aspecto influenciador nas decisões da $\mathrm{MN}$; que há hierarquia nas tomadas de decisões; e que os participantes do coletivo absorvem uma espécie de identidade profissional parecido com o que os jornalistas fazem para buscarem uma identificação com seu campo de atuação.

Não pretendemos encaixar a $\mathrm{MN}$ em um determinado modelo midiático. No caso específico estudado por este artigo, o grupo optou por fazer a defesa do ex-presidente, e ter uma posição definida, e expô-la, não é demérito, pelo contrário, é louvável. Um aspecto que merece ser destacado, pois é neste ponto que a MN, enquanto coletivo midiático, propõe-se a se diferenciar dos meios jornalísticos tradicionais. Enquanto a mídia corporativa insiste em "vender" ao público que seu trabalho é objetivo, imparcial, mesmo com todas as evidências científicas e empíricas que mostram o contrário (Alsina, 2009; Costa, 2009; Hernandes, 2006), a Mídia Ninja deixa claro que bandeiras defende.

A objetividade enquanto [...] "um dos recursos jornalísticos para se tentar 'apagar' o modo pelo qual a realidade foi filtrada a partir do sistema de valores do jornal [...]" (Hernandes, 2006, p. 30) é uma construção da imprensa comercial para que o público acredite que nas partes informativas do produto jornalístico, a notícia consegue ser isenta, ao apresentar os vários lados da história, desconsiderando os enquadramentos, questões organizacionais, subjetividades, repertório de quem escreveu e editou o material etc.

Embora não tenha sido objetivo deste trabalho avaliar a veracidade das informações publicizadas pela MN, é preciso atentar para um ponto crucial: o que se faz para defender seu ponto de vista. Esconde-se ou distorce-se fatos? No jornalismo tradicional há inúmeros casos de distorção deliberada e inadvertida da informação (Bucci, 2000). Isso acontece no caso dos coletivos midiativistas? É algo que pode ser estudado em pesquisas posteriores. É importante abordar este ponto, pois a $\mathrm{MN}$ se apresenta também como um grupo jornalístico. Percebe-se então que o coletivo quer absorver esse ethos (Mainguineau, 2008), mesmo questionando a forma tradicional e comercial sobre a qual o campo jornalístico se estruturou, principalmente no século XX (Alsina, 2009). Foletto (2017), após realizar uma 
minuciosa pesquisa etnográfica, indicou que o jornalismo é uma das práticas empreendidas pelo grupo, não a principal. A própria gênese da $\mathrm{MN}$, surgida a partir de um coletivo cultural, o FdE, indica que o jornalismo é mais uma referência (da qual são apropriadas técnicas de coleta e divulgação de informações, como entrevistas e reportagens), do que um norte a ser seguido.

De uma maneira ou de outra, uma transformação está em curso. A liberação do polo emissor da informação e a perda do status do jornalismo como agente principal responsável por fazer a ponte entre os acontecimentos e o público no geral proporcionam a quem tiver interesse, mesmo com a formação das chamadas bolhas ideológicas, a possibilidade de buscar novas fontes de informação e formar sua visão de mundo da maneira mais plural possível.

\section{Notas}

${ }_{1}$ Pesquisa financiada, em parte (na etapa de finalização do artigo), pela Capes durante período de doutorado sanduíche realizado pelo autor Raul Ramalho, na Universidade da Beira Interior, em Portugal.

\section{Referências}

ALMEIDA, T. D. R. Midiativismo e cobertura jornalísticas: mídia Livre, movimentos em rede e estratégias de contrapoder. 2015. 165f. Dissertação (Mestrado Profssional em Jornalismo) Centro de Comunicação Turismo e Artes, Universidade Federal da Paraíba, João Pessoa, 2015. Disponível em: http://bdtd.ibict.br/vufind/Record/UFPB_a76801a5cee4980d60d95972f691039e. Acesso em 14 mai. 2017.

ALSINA, M. R. A construção da notícia. Petrópolis: Vozes: 2009.

BAITELLO JÚNIOR, N. A era da inconofagia: reflexões sobre a imagem, comunicação, mídia e cultura. São Paulo: Paulus, 2014.

BAUMAN, Z.; RAUD, R. A individualidade numa época de incertezas. Rio de Janeiro: Zahar, 2018.

BENTES, I. Mídia-Multidão: estéticas da comunicação e biopolíticas. Rio de Janeiro: Mauad X, 2015.

BEZERRA, A. K. G. O mito Lula: política, discursos e cenário midiático. 2011. 334f. Tese (Doutorado em Ciências Sociais) - Centro de Humanidades, Universidade Federal de Campina Grande, Campina Grande, 2011. 
BOSCO, F. A vítima tem sempre razão? Lutas identitárias e o novo espaço público brasileiro. São Paulo: Todavia, 2017.

BRAIGHI, A. A. Análise do discurso midiativista: uma abordagem às transmissões simultâneas do Mídia Ninja. 2016. 654f. Tese (Doutorado em Linguística do Texto e do Discurso) - Faculdade de Letras, Universidade Federal de Minas Gerais, Belo Horizonte, 2016.

; CÂMARA, M. T. O que é Midiativismo? Uma proposta conceitual. In: BRAIGHI, A. A.; LESSA, C.; CÂMARA, M. T. (orgs.). Interfaces do Midiativismo: do conceito à prática. CEFETMG: Belo Horizonte, 2018. p. 25-42. Disponível em:

https://interfacesdomidiativismo.wordpress.com/. Acesso em: 15 jul. 2018.

BUCCI, E. Sobre ética e imprensa. São Paulo: Companhia das Letras, 2000.

CASTELLS, M. Redes de indignação e esperança: movimentos sociais na era da internet. 2. ed. Rio de Janeiro: Zahar, 2017.

CHIZZOTTI, A. Pesquisa qualitativa em ciências humanas e sociais. Petrópolis: Vozes, 2006.

COSTA, C. T. Ética, jornalismo e nova mídia: uma moral provisória. Rio de Janeiro: Jorge Zahar, 2009.

DI FELICE, M. Net-ativismo: da ação social para o ato conectivo. São Paulo: Paulus Editora, 2017.

FAIRCLOUGH, N. Discurso e mudança social. Brasília: Editora Universidade de Brasília, 2001.

FOLETTO, L. F. Um mosaico de parcialidades na nuvem coletiva: rastreando a Mídia Ninja (2013 - 2016). 2017. 224f. Tese (Doutorado em Comunicação e Informação) - Faculdade de Biblioteconomia e Comunicação, Universidade Federal do Rio Grande do Sul, Porto Alegre, 2017. Disponível em: https://www.lume.ufrgs.br/handle/10183/158675. Acesso em: 9 mar. 2018.

FOUCAULT, M. Arqueologia do saber. 8. ed. Rio de Janeiro: Forense Universitária, 2008. HERNANDES, N. A mídia e seus truques: o que jornal, revista, TV, rádio e internet fazem para captar e manter a atenção do público. São Paulo: Contexto, 2006.

HOMERO. Odisseia. Tradução: WERNER, Christian. São Paulo: Cosac \& Naify, 2014.

LEAL, M.; MARTINS, E. Entre o ativismo midiático e o jornalismo: os valores-notícia e as práticas produtivas nas narrativas da Mídia Ninja. In: BRAIGHI, A. A.; LESSA, C.; CÂMARA, M. T. (Orgs.). Interfaces do Midiativismo: do conceito à prática. CEFET-MG: Belo Horizonte, 2018. p. 533-553. https://interfacesdomidiativismo.wordpress.com/. Acesso em: 15 jul. 2018.

LÉVY, P. A esfera pública do século XXI. In: DI FELICE, M.; PEREIRA, E.; ROZA, E. (Orgs.). Net-ativismo: redes digitais e novas práticas de participação. Campinas, SP: Papirus, 2017. P. 29-38.

MAINGUENEAU, D. Discurso e análise do discurso. São Paulo: Parábola Editorial, 2015.

A propósito do ethos. In: MOTTA, A. R.; SALGADO, L. (Orgs.). Ethos discursivo. São Paulo: Contexto, 2008, p. 11-29. 
MALINI, F.; ANTOUN, H. @ internet e \#rua: ciberativismo e mobilização nas redes sociais. Porto Alegre: Sulina, 2013.

MALINI, F. Como o discurso de ódio amplia a viralidade do noticiário político no Facebook. Laboratório de estudos sobre imagem e cibercultura, 2017. Disponível em:

http://www.labic.net/cartografia/como-o-discurso-de-odio-amplia-a-viralidade-do-noticiariopolitico-no-facebook/. Acesso em: 12 jan. 2018.

MÍDIA NINJA. Quem somos. 201-. Disponível em: https://www.facebook.com/164188247072662/posts/1201156186709191/. Acesso em: 12 ago. 2018.

PARISER, E. O filtro invisível: o que a internet está escondendo de você. Rio de Janeiro: Zahar, 2012.

PRADO, M. Ciberativismo e noticiário: da mídia torpedista às redes sociais. Rio de Janeiro: Alta Books, 2015.

RAMALHO, R.; MAIA, K. Estudos metodológicos: a aplicação da análise de discurso para interpretar a produção de sentido de coletivos midiativistas. Verso e Reverso, São Leopoldo, 32(81), p. 187-200, setembro-dezembro 2018. Disponível em:

http://revistas.unisinos.br/index.php/versoereverso/article/viewFile/ver.2018.32.81.02/60746547 . Acesso em 3 jan. 2019.

RAMONET, I. A explosão do jornalismo: das mídias de massa à massa de mídias. São Paulo: Publisher Brasil, 2012.

RECUERO, R. Redes Sociais na internet, difusão de informação e jornalismo: elementos para discussão. In: SOSTER, D. A.; SILVA, F. F. (Orgs.). Metamorfoses jornalísticas 2: a reconfiguração da forma. Santa Cruz do Sul: UNISC, 2009. p. 39-55. Disponível em: http://www.raquelrecuero.com/artigos/artigoredesjornalismorecuero.pdf. Acesso em: 8 set. 2018.

. Introdução à análise de redes sociais. Salvador: EDUFBA, 2017. Disponível em: https://repositorio.ufba.br/ri/handle/ri/24759. Acesso em: 5 fev. 2018.

RODRIGUES, C.; BARONI, A. Ethos jornalístico: Mídia Ninja e um campo em contestação. Brazilian Journalism Research, Brasília, v. 14 - oㅡ 2, p. 568-593, 2018. Disponível em: https://bjr.sbpjor.org.br/bjr/article/view/992. Acesso em: 2 set. 2018

RODRIGUES, C. O cinema e a produção. Para quem gosta, faz ou que fazer cinema. 3.ed. Rio de Janeiro: Lamparina, 2007.

SILVA, F. F.; RODRIGUES, A. A. Jornalismo em mobilidade: redes sociais e cobertura dos protestos "ao vivo" e da rua. In: BARRETO, E. et al. (orgs.). Mídia, tecnologia e linguagem jornalística. João Pessoa: Editora do CCTA, 2014, p. 26-43.

ZEN, D. Entenda o habeas corpus expedido para Lula. 2018. Disponível em: http://midianinja.org/danielzen/entenda-o-habeas-corpus-expedido-para-lula/. Acesso em: 12 ago. 2018.

Yin, R. K. Estudo de caso: planejamento e métodos. 2. ed. Porto Alegre: Bookman, 2001. 


\section{As autoras}

Raul Ramalho é jornalista, mestre em jornalismo (UFPB) e doutorando no Programa de PósGraduação em Estudos da Mídia da UFRN. raulramalhojornalistacg@gmail.com

Kênia Maia é doutora em Ciência da Informação e da Comunicação pela Université de Metz, atual Université de Lorraine. Professora do Programa de Pós-Graduação em Estudos da Mídia da UFRN. kbiamaia@gmail.com 